\title{
Morfologia da flor, fruto e plântula de Victoria amazonica (Poepp.) J.C. Sowerby (Nymphaeaceae)
}

\author{
Sônia Maciel da ROSA-OSMAN ${ }^{1}$, Robson RODRIGUES², Maria Sílvia de MENDONÇA³, Luiz Antonio de \\ SOUZA $^{4}$, Maria Teresa Fernandez PIEDADE 5 \\ RESUMO \\ Victoria amazonica (Poepp.) J.C. Sowerby é uma hidrófita que ocorre nas várzeas de águas brancas e igapós da Bacia Amazônica \\ e na Bacia do rio Paraguai. A morfologia da flor, fruto e plântula/"tirodendro" é objeto do presente trabalho. O material \\ botânico foi coletado em Parintins e Manaus, estado do Amazonas, Brasil. A análise morfológica foi feita em material fresco \\ e fixado em FAA 50. O desenvolvimento das plântulas foi realizado no escuro em frascos com água com teor reduzido de \\ oxigênio. As flores possuem pedicelo longo e são hemicíclicas, diclamídeas, monoclinas e com antese vespertina. Os frutos \\ são carnosos, indeiscentes, com pseudossincarpia. As sementes apresentam arilo que atua na dispersão pela água. As plântulas \\ se desenvolvem em condiçóes de hipoxia e apresentam um cotilédone exposto acicular. $\mathrm{O}$ "tirodendro" apresenta eofilos com \\ heterofilia. As flores apresentam caracteres morfológicos básicos da família, a definição do tipo de fruto exige estudo ontogenético \\ e a heterofilia é um caráter típico de plântulas/"tirodendros"de Nymphaeaceae.
}

PALAVRAS-CHAVE: Angiospermas basais, pseudossincarpia, semente, heterofilia, cotilédone acicular.

\section{Morphology of flower, fruit and seedling of Victoria amazonica (Poepp.) J.C. Sowerby (Nymphaeaceae)}

\begin{abstract}
Victoria amazonica (Poepp.) J.C. Sowerby is a hydrophyte that occurs in the white water leas and igapos of the Amazonian and Paraguay Basin. The flower, fruit and seedling/"tirodendro" morphology is the object of the present work. The botanical material was collected at Parintins and Manaus, Amazonian state, Brazil. The morphological analysis was made in both fresh and fixed material. The seedling development was accomplished in flasks with water containing little oxygen and maintained in the darkness. Flowers present long pedicel and they are hemicyclic, dichlamydeous, bisexual with vespertine anthesis. Fruits are fleshy, indehiscent with pseudo-syncarpy. Seeds present aril that acts in the water dispersion. Seedlings grow in hypoxy conditions and they present an acicular and exposed cotyledon. The "tirodendro" stage presents eophylls with heterophylly. Flowers present basic morphologic characters of the family, the definition of the fruit type demands ontogenetic study and the heterophylly is a typical character of Nymphaeaceae seedlings/ "tirodendros".
\end{abstract}

KEYWORDS: Basal angiosperms, pseudo-sincarpy, seed, heterophylly, acicular cotyledon

\footnotetext{
1 Instituto Nacional de Pesquisas da Amazônia, E-mail: smrosa@inpa.gov.br

2 Instituto Nacional de Pesquisas da Amazônia, E-mail: robsonfebra@yahoo.com.br

3 Instituto Nacional de Pesquisas da Amazônia, E-mail: msilvia@ufam.edu.br

${ }^{4}$ Universidade Estadual de Maringá, E-mail: lasouza@uem.br

${ }^{5}$ Instituto Nacional de Pesquisas da Amazônia, E-mail: maitepp@inpa.gov.br
} 


\section{INTRODUÇÃO}

As áreas alagáveis dos grandes rios da Bacia Amazônica são ecossistemas específicos com alta biodiversidade $\mathrm{e}$ grande número de plantas e animais endêmicos. Além disso, principalmente as várzeas do Rio Solimóes-Amazonas e dos afluentes de água branca têm grande potencial produtivo para a pesca, agricultura, pecuária e para a silvicultura (Junk 1998). Com o aumento da exploração desses recursos naturais pelo ser humano este ecossistema está sendo impactado, colocando em risco as plantas e animais que nele vivem.

As várzeas de águas brancas ou barrentas sáo altamente produtivas e chamam a atenção pela fertilidade de seus solos e pela riqueza de macrófitas aquáticas. Já os igapós, de águas pretas e claras, possuem solos pobres em nutrientes e águas ácidas, apresentando menor riqueza de espécies de plantas herbáceas (Junk 1983). Dentre as espécies de plantas aquáticas, que ocorrem tanto nas várzeas quanto nos igapós, destaca-se Victoria amazonica (Poepp.) J.C. Sowerby (Nymphaeaceae).

A família Nymphaeaceae está distribuída no mundo todo, incluindo seis gêneros e cerca de 60 espécies, a maioria em Nymphaea. No Novo Mundo, ocorrem 21 espécies, 15 em Nymphaea, duas em Victoria e uma em Nuphar (N. advena). Devido às flores tipicamente grandes e vistosas, várias espécies são utilizadas como ornamentais e algumas espécies exóticas, introduzidas para a decoração de ambientes, passaram a ocorrer de maneira subespontânea (Souza e Lorenzi 2005).

Victoria Lindl. é gênero nativo do Brasil (Souza e Lorenzi 2005) e, juntamente com Euryale Salisb., apresenta apomorfia de acúleos no pecíolo e superfície da face abaxial da folha, assim como ambos os gêneros são considerados acaulescentes e ervas de vida curta (Judd et al. 2002). Judd et al. (2002) registram, ainda, que a anatomia floral indica que Nymphaea L. pode ser um grupo irmão do clado Victoria + Euryale.

Victoria amazonica é uma herbácea aquática, fixa, com folhas flutuantes, encontrada em águas calmas e com temperatura em torno de 26 a $30{ }^{\circ} \mathrm{C}$, sendo originária da regiâo equatorial da Bacia do Rio Amazonas (Prance 1974). Segundo Decker (1936) e Pott \& Pott (2000), além da Amazônia esta espécie também ocorre no Pantanal e na Bacia do Paraguai. Em 1836 a planta foi descrita como Euryale amazonica, mas depois de quatorze anos houve mudança para o gênero Victoria. O nome do gênero Victoria foi atribuído por Lindley (1837) em homenagem à Rainha Victoria da Inglaterra (Hoehne 1948).

Popularmente, a planta é conhecida como "vitória-régia", "forno-d'água", "rainha-dos-lagos", "milho-d'água”, entre outros. A espécie possui grandes folhas orbiculares com bordos levantados em ângulo reto, flores grandes de até $33 \mathrm{~cm}$ de diâmetro, sementes elíptico-globulares e muitos espinhos em toda planta, dificultando, por este fato, o manuseio, o que limitou estudos sobre sua biologia e ecologia (Hoehne 1948).

A folha de Victoria amazonica é considerada medicinal (depurativa e cicatrizante). O suco serve para tingir o cabelo de preto e dar brilho, serve também para o curtimento de peles e couros finos. A semente do tamanho de um grão de ervilha é comestível, sendo rica em ferro e amido, estoura no calor e é saborosa, como pipoca, sendo também alimento de juritis e roedores. O rizoma e o pecíolo também são comestíveis (Hoehne 1948, Pio Corrêa 1952, Pott e Pott 2000).

Victoria amazonica pertence à Nymphaeaceae (Salisb) possui importância ecológica, medicinal e alimentícia. Provavelmente é a espécie da região Amazônica mais conhecida no mundo, com grande valor ornamental, e muito apreciada nas estufas da Europa e América do Norte. Na literatura são registradas informaçóes relativas à sua morfologia floral (Pio Correia 1952), ao processo de antese e de polinização (Gessner 1960, 1962, Seymor e Matthews 2006), à morfologia do estame (Heinsbroek e Heel 1969), à antese (Sculthorpe 1985) e à pseudossincarpia do ovário (Weberling 1992).

Considerando-se a importância ecológica, econômica e estudos morfológicos sobre Victoria amazonica, o presente trabalho teve por objetivo caracterizar morfologicamente a flor, o fruto e a plântula/"tirodendro" nos ambientes naturais de ocorrência e em condiçóes controladas de laboratório. É importante ressaltar que a investigação sobre frutos/sementes e plântulas da aquática Victoria amazonica é uma contribuição ao estudo de propágulos e plântulas de espécies nativas da Amazônia, que, atualmente, tem se voltado mais para plantas arbóreas florestais (Camargo et al. 2008).

\section{MATERIAL E MÉTODOS}

As coletas do material botânico (folhas, flores, frutos, sementes e plantas jovens) foram realizadas nas proximidades do município de Manaus, no Lago Cataláo (ambiente de transição - águas mistas) e no Lago da Felicidade (ambiente de igapó), próximo à confluência com o Rio Negro, sob as coordenadas $03^{\circ} 15^{\prime} \mathrm{S}$ e $60^{\circ} 00^{\prime} \mathrm{W}$. Também foram feitas coletas no Município de Parintins no Lago do Aninga (ambiente de igapó) e no Lago da Vila Amazônica (ambiente de várzea). $\mathrm{O}$ material botânico coletado em campo foi acondicionado em bacias gerbox com um pouco de água para evitar a desidratação, depois colocado em sacos plásticos umedecidos e levado ao laboratório. Parte deste material foi usado para fixação em FAA 50 (Johansen 1940), para análises morfológicas e para obtenção de sementes. Porçôes da folha adulta e da flor foram herborizadas e depositadas no Herbário do INPA (Instituto Nacional de Pesquisas da Amazônia, Manaus, estado do Amazonas, Brasil), sob número de registro 215811 . 
As flores, frutos e sementes foram dissecados e analisados com auxílio de microscópio estereoscópico. A terminologia adotada para descrição morfológica destes órgãos baseou-se em Hoehne (1948), Corner (1976), Weberling (1992), Barroso et al. (1999) e Judd et al. (2002).

As sementes coletadas em Parintins (Lago da Vila Amazônica) foram acondicionadas em potes fechados com água, pouco oxigênio dissolvido e no escuro. Foi utilizado um oxímetro (OXI-330) para medir o oxigênio dissolvido na água e a temperatura pós-germinação. Após a germinação, caracterizada pela protrusão do eixo embrionário, as plântulas e "tirodendros", em diversas fases de desenvolvimento, foram fixadas em FAA 50 (Johansen 1940) para posterior análise morfológica. Plântula é a fase que abrange o vegetal desde a germinaçáo consumada da semente até a formaçáo da primeira folha ou eofilo. Após esta fase, o estágio seguinte é o "tirodendro", que compreende o final do desenvolvimento do primeiro eofilo da plântula até o momento em que aparecem os primeiros metafilos (Souza 2003). A terminologia adotada para o estudo morfológico da plântula e "tirodendro" foi baseada em Sculthorpe (1985) e Souza et al. (2009).

As ilustraçóes morfológicas foram feitas mediante desenhos e fotografias. Os desenhos foram elaborados em microscópio estereoscópico Leitz equipado com câmara clara. As fotografias foram obtidas com câmera digital.

Além da análise morfológica das estruturas reprodutivas e do desenvolvimento da plântula, foram feitas observaçóes de campo sobre o processo de polinização e do desenvolvimento de frutos.

\section{RESULTADOS E DISCUSSÃO}

\section{Morfologia da flor}

As flores são solitárias e axilares. Possuem um pedúnculo muito longo que oscila de acordo com a profundidade do local e a fase do ciclo hidrológico, podendo medir de três a oito metros de comprimento. A flor (Figura 1A,B) é hemicíclica, monoclina, diclamídea, heteroclamídea, com corola dialipétala. $\mathrm{O}$ cálice é dialissépalo, com quatro sépalas coriáceas, marrom-escuras com bordas róseo-esverdeadas, sendo três delas sépalas petalóides nas bordas e coriáceas no centro. As sépalas têm nervação paralela e são recobertas externamente por espinhos com a função provável de proteção.

Pio Corrêa (1952) registrou a descrição morfológica da flor de Victoria amazonica, considerando-a como aromática, acíclica, com cálice tetrafilo e com 100 pétalas distribuídas espiraladamente, sendo as exteriores de coloraçáo branco-pura e de formato oblongo, côncavo e obtuso, e as pétalas interiores mais estreitas e acuminadíssimas.

A antese e a polinização de Victoria amazonica foram objetos de investigação por diferentes autores. A flor possui coloração branco-creme logo após a antese, quando exala um odor agradável que atrai os insetos polinizadores no fim da tarde e que foram identificados como besouros do gênero Cyclocephala (Prance e Arias 1975). Para estes autores, no processo da antese ocorrem reaçôes químicas no interior da flor, ocasionando um aumento de temperatura de até $11^{\circ} \mathrm{C}$ acima da temperatura ambiente; dessas reaçóes resulta elevada produçáo de antocianina que proporciona a mudança de cor do perianto para roxo. Gessner $(1960,1962)$ registrou que a abertura da flor, processada no final da tarde, sofre influência da intensidade luminosa e que a polinização é feita pelo besouro escarabeídeo Cyclocephala castanea Oliv.

Observaçóes feitas no ambiente de coleta do material botânico confirmaram a abertura da flor ao entardecer. A contagem dos besouros Cyclocephala castanea Oliv polinizadores revelou em média $23 \pm 1,22$ besouros $(\mathrm{N}=5)$, que são atraídos pelo odor e coloração branca das flores, permanecendo presos na flor por cerca de 24 horas. A grande quantidade de besouros dentro da flor levou à predação dos óvulos, verificada em cinco flores e confirmada pela baixa quantidade de sementes presentes em frutos desenvolvidos no Lago da Felicidade, em relação ao potencial médio de $114 \pm$ 1,34 sementes produzidas por fruto $(\mathrm{N}=3)$. Após a possível fecundaçáo, os besouros foram liberados da flor que manteve o cálice e a corola parcialmente deteriorados (Figura 1A). Em seguida, durante um período aproximado de 30 dias, a flor submerge para o desenvolvimento do fruto, emergindo para a superfície somente quando este amadurece, liberando as sementes que são dispersas pela água (hidrocoria).

$\mathrm{O}$ androceu (Figura 1B) é formado por muitos estames férteis, gamostêmones na base, dispostos em círculos. Os estames são laminares (Figura 1B,E), desprovidos de conectivo. As anteras são elípticas e rimosas. $\mathrm{O}$ androceu também apresenta estaminódios (Figura 1C) laminares sem tecas e estaminódio com tecas rudimentares, localizados externamente aos estames. Weberling (1992) considerou que os estames laminares, que são comuns em Nymphaeaceae, constituem um exemplo clássico da natureza foliar dos estames.

O gineceu (Figura 1B,D) é formado por ovário semiínfero de superfície espinescente, com 33 a 46 carpelos por flor, estilete e estigma curtos, ovais, pontiagudos e rígidos que se localizam no centro da cavidade situada acima do ovário. $\mathrm{O}$ ovário apresenta parênquima mais compacto na regiáo subepidérmica e na região central e aerênquima nas proximidades dos lóculos; a porção central do ovário é muito vascularizada (Figura 1D). Sculthorpe (1985) descreveu o gineceu de Victoria amazonica, caracterizando-o como sincárpico, multicarpelar, multilocular, com ovário ínfero recoberto por espinhos para proteção contra os predadores aquáticos, com óvulos anátropos e parietais. $\mathrm{Na}$ literatura 

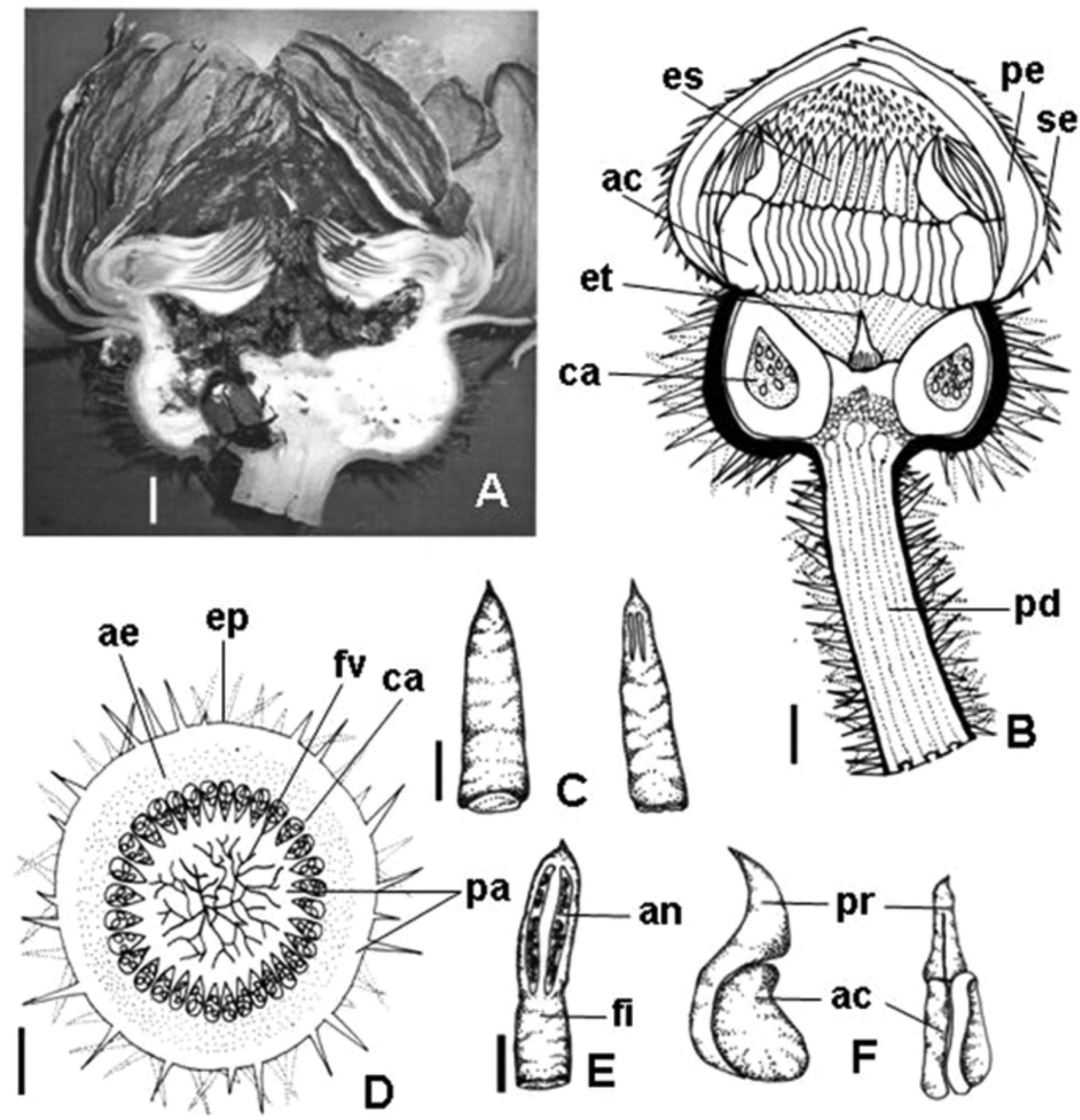

Figura 1 - Morfologia da flor de Victoria amazonica. Fig. A - Flor secionada longitudinalmente com um besouro Cyclocephala. Fig. B - Botão floral secionado longitudinalmente. Fig. C - Estaminódios. Fig. D - Ovário em seção transversal. Fig. E - Estame laminar. Fig. F - Dois paracarpelos com apêndices carpelares. (ac = apêndice carpelar; ae = aerênquima; an = antera; $c a$ = carpelo; ep = epiderme; es = estame; et = estigma; $f i=$ filete; fv = feixe carpelar; pa = parênquima; $p d=$ pedicelo com aerênquima; $p e=$ pétala; $p r=$ paracarpelo; se $=$ sépala). Barras $=1 \mathrm{~cm}(A, B, D), 0,5 \mathrm{~cm}(C, E, F)$.

registra-se discussão sobre a natureza apocárpica ou sincárpica do gineceu dessa espécie. Victoria amazonica é uma espécie de Nymphaeaceae que pertence ao grupo filogenético das angiospermas basais, que comumente apresenta, entre outros caracteres, gineceu com carpelos distintos e livres (Judd et al. 2002). Estes autores, entretanto, referem-se a carpelos livres ou unidos para a família. Por outro lado, Weberling (1992), considerou o ovário de espécies de Nymphaeaceae, incluindo Victoria amazonica, como pseudossincárpico com base na fusão dos carpelos ao tecido axial central da flor e na existência de fendas intercarpelares. Realmente, como observado no presente estudo, o ovário de Victoria amazonica pode ser considerado como pseudossincárpico, náo pela presença de fendas intercarpelares, que não foram observadas nos ovários das flores coletadas no presente trabalho, mas sim pela fusão carpelar ao eixo floral central (Figura 1B,D).

$\mathrm{Na}$ flor de Victoria amazonica ocorrem os paracarpelos (Figura 1F) que são estruturas estéreis, de consistência rígida, de ápice afilado e que apresentam uma fenda central. $\mathrm{Na}$ base de cada paracarpelo ocorrem dois apêndices carpelares que são carnosos e ricos em amido. Estes apêndices são visíveis e intactos apenas no botáo floral, pois na flor aberta são consumidos por besouros. Prance e Arias (1975), que registraram primeiro a presença de amido nos apêndices carpelares, sugeriram que eles servem como alimento para os besouros polinizadores dessa espécie.

\section{Morfologia do fruto}

$\mathrm{O}$ fruto se desenvolve no interior da água, emergindo quando maduro. $\mathrm{O}$ fruto (Figura 2A) é carnoso, indeiscente, globoso, verde, multicarpelar, com muitas sementes ligadas pelo funículo à parede do fruto e revestido abundantemente por espinhos. Possui no ápice uma depressão de contorno oval, que acumula restos de perianto apodrecido (Figura 2A) que exala odor fétido. 
Sáo registrados tipos diferentes de frutos para Nymphaeaceae. Arber (1920) e Pio Corrêa (1952) registraram o fruto como baga globosa, com até $14 \mathrm{~cm}$ de diâmetro, semelhante à cápsula, que acumula mucilagem facilitando a absorção de água. Roth (1977) considerou que Nymphaeaceae apresenta fruto agregado como resultado do desenvolvimento de gineceu multipistilado apocárpico. Spjut (1994) relacionou dois tipos de frutos para a família: o hesperídeo, que se caracteriza como fruto simples indeiscente com placentação axilar e pericarpo carnoso coriáceo e o tipo ceratium, considerado como fruto capsular que se abre por separação ou rompimento das camadas do pericarpo. Barroso et al. (1999) registraram como fruto simples bacáceo plurilocular, que pode se romper na maturação. Judd et al. (2002) reconheceram três tipos diferentes de frutos para a família, como fruto agregado, baga e cápsula carnosa que se abre irregularmente.

No caso de Victoria amazonica, o fruto mostra caracteres morfológicos que o aproxima do tipo hesperídeo, mas a pseudossincarpia do gineceu pode caracterizá-lo como fruto agregado. Assim, a definiçáo do tipo de fruto desta espécie exige estudo anatômico ontogenético adicional.

\section{Morfologia da semente}

As sementes são globosas, ariladas, com tegumento rígido de coloração castanha. $\mathrm{O}$ arilo, que envolve quase toda a semente, tem consistência mucilaginosa e acumula ar, o que facilita a flutuação da semente no processo de dispersão pela água. A semente apresenta embrião reduzido e abundante reserva farinácea (Figura 2B,C,D).
O arilo de Victoria amazonica é referido na literatura como de origem funicular e como estrutura aerífera que desempenha papel importante no processo de hidrocoria da espécie (Corner 1976, Werker 1997, Barroso et al. 1999). No caso do tipo de reserva que essa espécie apresenta na semente, estes autores registram-na como perisperma.

As sementes de Victoria amazonica são recalcitrantes e dormentes, em razáo da presença de tegumento resistente e do arilo que contém substâncias inibidoras (Ferreira e Borghetti 2004). Para Ferraz e Sampaio (1996) é possível que uma semente seja recalcitrante e dormente ao mesmo tempo, o que dependerá das condiçôes ideais necessárias para seu estabelecimento.

No presente estudo, observaçôes de campo sobre as sementes de Victoria amazonica revelaram que elas de fato não toleram dessecamento após dispersão, daí o meio úmido adequado do pericarpo carnoso que envolve essas sementes. Outro fator que deve contribuir com o ambiente úmido propício às sementes é o período em que elas são dispersas na regiáo deste estudo, o mês de junho, quando ocorre o pico de inundação na regiâo.

\section{Morfologia da plântula}

As sementes germinaram em condiçóes de hipoxia, ou seja, em água com concentraçôes máximas de apenas $0,37 \mathrm{mg} / \mathrm{l}$, que equivale a $4,7 \%$ de oxigênio dissolvido, em temperatura de $29^{\circ} \mathrm{C}$ e no escuro. Essas condiçóes são verificadas no ambiente natural de Victoria amazonica, onde as sementes são dispersas pela água, perdem o arilo (estrutura responsável pela

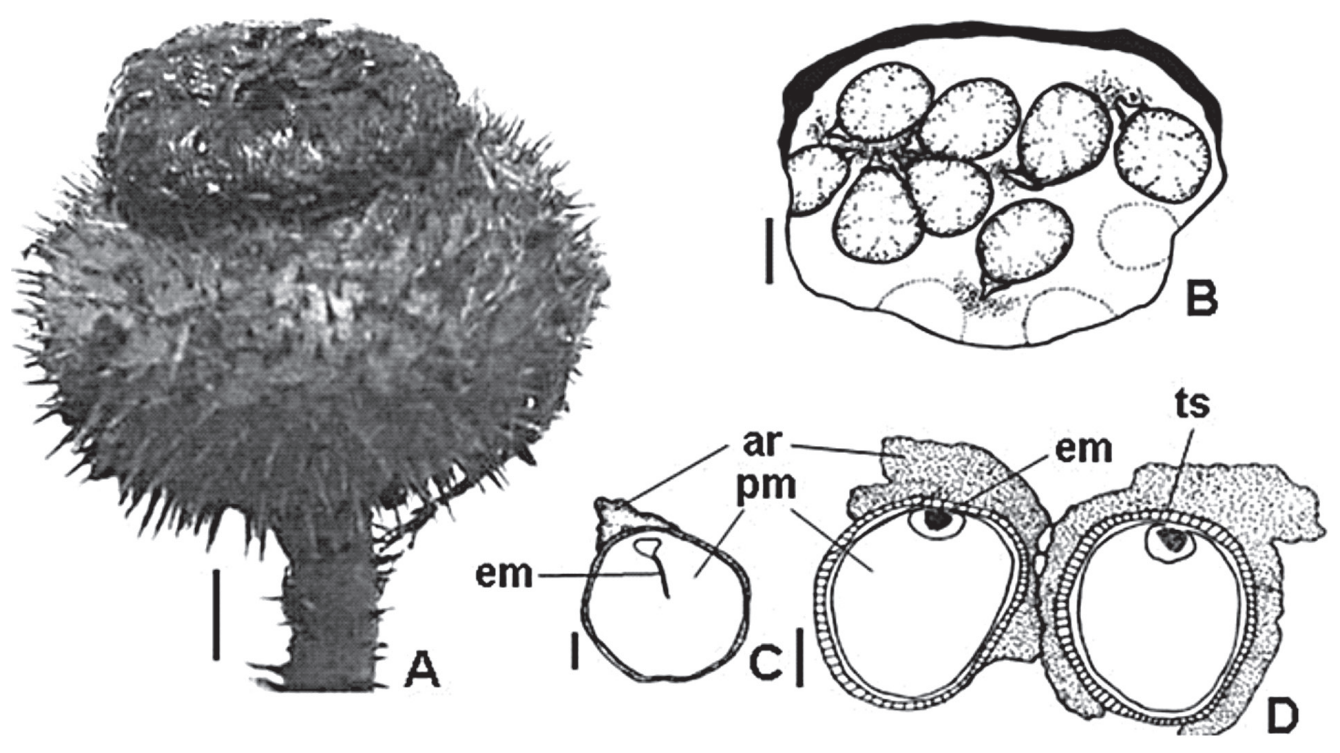

Figura 2 - Morfologia do fruto e da semente de Victoria amazonica. Fig. A - Aspecto geral do fruto. Fig. B - Sementes ligadas ao carpelo. Figs. C e D - Sementes jovem e madura secionadas longitudinalmente. $(\mathrm{ar}=$ arilo; em = embrião; $\mathrm{pm}=$ perisperma; ts = tegumento seminal). Barras $=1,5 \mathrm{~cm}(A), 2 \mathrm{~cm}(\mathrm{C}, \mathrm{D})$, $2,5 \mathrm{~cm}(\mathrm{~B})$. 
flutuação), afundam e germinam. Se as condiçôes forem de seca, as sementes mantêm-se dormentes, germinando somente no período de cheia dos rios.

O início da fase de plântula se dá com a protrusão do eixo embrionário na superfície da semente. Em sequência, desenvolvem-se de forma mais ou menos concomitante a raiz primária e um dos cotilédones (Figura $3 \mathrm{~A}, \mathrm{~B}$ ). O outro cotilédone é muito reduzido e permanece no interior da semente. A raiz primária tem desenvolvimento reduzido (Figura 3C,D), sendo logo substituída por raízes adventícias (Figura 3E), característica muito comum nas monocotiledôneas e na família Nymphaeaceae. O cotilédone externo aclorofilado é formado por limbo aciculado e bainha (Figura 3D,E). Quando ocorre o surgimento do eofilo, este cotilédone se curva e seca. $\mathrm{O}$ eofilo (Figura 3E) tem formato hastado, com base sagitada e ápice acuminado. Com a completa expansão do eofilo, as raízes adventícias mostram-se bem desenvolvidas (Figura 3E). Na planta adulta são as raízes adventícias que a fixam ao substrato.

$\mathrm{Na}$ fase de "tirodendro" ocorrem vários tipos de eofilos com formato lanceolado-hastado, deltoide-hastado, peltado e orbicular. Os eofilos orbiculares diferem do metafilo orbicular na morfologia do bordo e por apresentarem espinhos menos rígidos na face abaxial do limbo e pecíolo mais fino e maleável. A heterofilia de Victoria amazonica, verificada na fase de

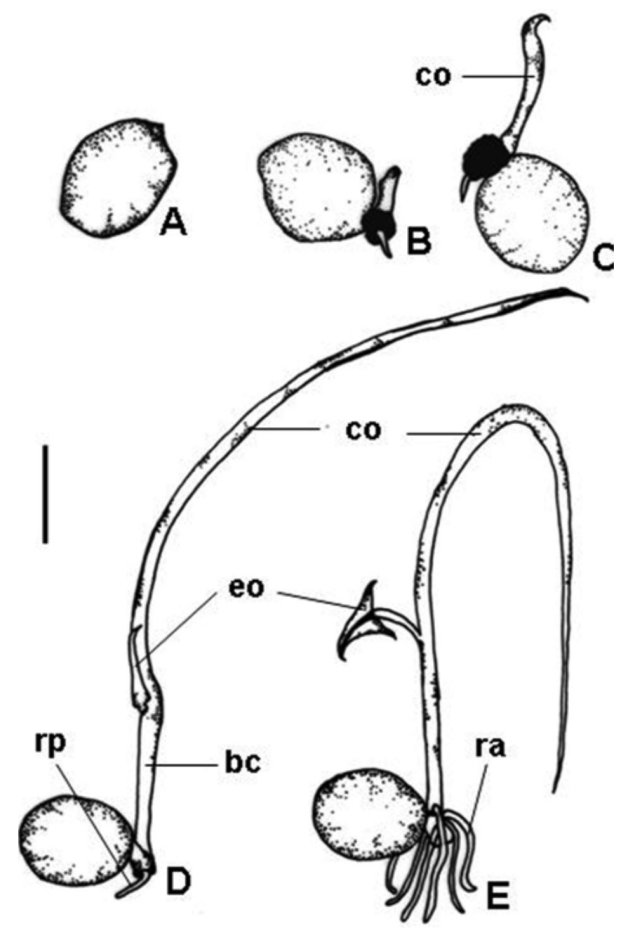

Figura 3 - Morfologia da plântula de Victoria amazonica. Fig. A - Semente. Figs. $\mathrm{B}$ a E - Diferentes fases de desenvolvimento da plântula. ( $b c=$ bainha cotiledonar; $c 0=$ cotilédone acicular; $\mathrm{eo}=$ eofilo; ra = raiz adventícia; $r p=$ raiz primária). Barra $=3,1 \mathrm{~mm}$. tirodendro, também foi registrada por Gwynne-Vaughan (1897), Hoehne (1948) e Sculthorpe (1985). Sculthorpe (1985) considerou que em Nymphaeaceae a heterofilia é restrita ao estágio de plântula ou a uma fase de crescimento anterior à presença de rizoma. De fato, em Victoria amazonica foi observado que a heterofilia ocorre na fase de tirodendro, antes do desenvolvimento do rizoma.

Os metafilos são orbiculares peltados e, enquanto primórdios, são protegidos por brácteas. Na planta adulta forma-se rizoma que pode produzir brotamento, após as cheias dos rios. Esse tipo de reprodução vegetativa constitui uma alternativa da espécie à reprodução sexuada por sementes.

\section{AGRADECIMENTOS}

São expressos agradecimentos à FAPEAM/CNPq, pela concessão de bolsa de mestrado à primeira autora, e ao Convênio INPA/Max-Planck de Limnologia pelo apoio financeiro à execuçấo do trabalho.

\section{BIBLIOGRAFIA}

Arber, A. 1920. Water plants: a study of aquatic angiosperms. University Press, Cambridge. 436pp.

Barroso, G.M.; Amorim, M.P.; Peixoto, A.L.; Ichaso, C.L.F. 1999. Fruits and seeds: morphology applied to the systematic of dicotyledons. Editora UFV, Viçosa. 443pp (in Portuguese).

Camargo, J.L.; Ferraz, I.D.K.; Mesquita, M.R; Santos, B.A.; Brum, H.D. 2008. Guide of Propagules and Seedlings of Amazonia. Volume I. Editora do INPA, Manaus. 168pp (in Portuguese).

Corner, E.J.H. 1976. The seeds of dicotyledons. Volume I. Cambridge University Press, New York. 311pp.

Decker, J.S. 1936. Biological aspects of Brazilian flora. Casa Editora, Roternurnd \& Co. 640pp (in Portuguese, with abstract in English).

Ferraz, I.D.K.; Sampaio, P.T.B. 1996. Simple storage methods for Andiroba seeds (Carapa guianensis Aubl. and Carapa procera D.C. Meliaceae). Acta Amazonica, 26: 137-144 (in Portuguese, with abstract in English).

Ferreira, A.G.; Borghetti, F. 2004. Germination: from basic to applied. Artmed, Porto Alegre. 323pp (in Portuguese).

Gessner, F. 1960. The opening of flowers of Victoria regia in dependence of light. Planta, 54: 453-463 (in German).

Gessner, F. 1962. The opening of flowers of Victoria regia in relation the light. Boletim do Museu Emilio Goeldi, Botânica, 17: 1-13 (in Portuguese, with abstract in English).

Gwynne-Vaughan, B.A. 1897. On some Points in the Morphology and Anatomy of the Nymphaeaceae. Plates XXI \& XXII. Keeper of the Jodrell Laboratory, Royal Gardens, Kew. 301pp.

Hoehne, F.C. 1948. Aquatic plants. Secretaria da Agricultura, São Paulo. 168pp (in Portuguese).

Heinsbroek, PG.; Heel, W.A. 1969. Note on the bearing of the patternof vascular bundles on the morphology of the stamens 
of Victoria amazonica (Poepp.) Sowerby. Proc. Koninklijke Nederlandse Akademie van Wetenschappen Amsterdam Series, 72: 431-444.

Johansen, D.A. 1940. Plant microtechnique. McGraw-Hill Book Company, New York. 790pp.

Judd, W.S.; Campbell, C.S.; Kellogg, E.A.; Stevens, P.F.: Donoghue, M.J. 2002. Plant Systematics: A phylogenetic approach. Sinauer Associates, Sunderland, Massachusets, USA. 576 pp.

Junk, W.J. 1983. The waters of the Amazon region. Amazôniadevelopment, integration and ecology. Editora Brasiliense, São Paulo. p. 45-100 (in Portuguese).

Junk, W.J. 1998. The várzea of the Solimôes-Amazon river: resources and concepts for the sustainable use. Anais do IV Simpósio de Ecossistemas Brasileiros. 48pp (in Portuguese).

Lindley, J. 1837. Victoria regia. W. Nicol, Shakespeare Press, London. p. 1-4.

Pio Corrêa, M. 1952. Dictionary of useful plants of Brazil and of the exotic cultivated. Ministério da Agricultura, Rio de Janeiro, v. 3. 646pp (in Portuguese).

Pott, V.J.; Pott, A. 2000. Aquatics plants of Pantanal. Embrapa, Brasília. 404pp (in Portuguese).

Prance, G.T. 1974. Victoria amazonica or Victoria regia? Acta Amazonica, 4: 5-8 (in Portuguese, with abstract in English).

Prance, G.T.; Arias, J.R. 1975. A study of the floral biology of Victoria amazonica (Poepp.) Sowerby (Nymphaeaceae). Acta Amazonica, 2: 109-139.
Roth, I. 1977. Fruits of angiosperms. In: Linsbauer, K. (ed.). Encyclopedia of Plant Anatomy. Vol.10. Gebrüder Borntraeger, Berlin. 522pp.

Sculthorpe, C.D. 1985. The biology of aquatic vascular plants. Edward Arnold Publishers, London. 610pp.

Seymour, R.S.; Matthews, P.G.D. 2006. The role of thermogenesis in the pollination biology of the amazon waterlily Victoria amazonica. Annals of Botany, 98: 11291135.

Souza, L.A.; Moscheta, I.S.; Mourão, K.S.M.; Albiero, A.L.M.; Montanher, D.R.; Paoli, A.A.S. 2009. Morphology of seedling and of tirodendro. In: Souza, L.A. (org.). Seeds and SeedlingsGermination, Structure and Adaptation. Toda palavra Editora, Ponta Grossa, Paraná. 119-190 (in Portuguese).

Souza, V.C; Lorenzi, H. 2005. Sistematic botany (Illustrated guide for identification of families of angiosperms of the Brasilian flora, based on APG II). Instituto Plantarum de Estudos da Flora, Nova Odessa, São Paulo. 640 pp (in Portuguese).

Spjut, R.W. 1994. A systematic treatment of fruit types. Memoirs of New York Botanical Garden, 70: 1-182.

Weberling, F. 1992. Morphology of flowers and inflorescences. Cambridge University Press, Cambridge. 405pp.

Werker, E. 1997. Seed anatomy. Gebrüder Borntraeger, Berlin. 430pp.

Recebido em 21/01/2010

Aceito em 24/05/2010 
